\title{
This Is Us: a Case Examination on Black Men in Therapy
}

\author{
Lawren Wooten $^{1} \cdot$ Ayana Jordan ${ }^{2} \cdot$ Kevin M. Simon ${ }^{3} \cdot$ Jessica A. Gold ${ }^{4}$
}

Received: 9 September 2020 / Accepted: 17 August 2021 / Published online: 7 September 2021

(c) Academic Psychiatry 2021

Media portrayals of Black people are of considerable importance for psychiatric trainees and the populations they serve. This is particularly true in this critical moment when the United States (US) grapples with dual pandemics disproportionately harming Black people [1], one a novel virus, the other racism. The latter can lead to Black people's, especially men's, death by excessive force and racist assumptions that they were "armed and dangerous" [2]. A crucial but often overlooked consequence of regularly airing these murders on television is secondary or vicarious trauma [3]. Mainstream media rarely shows positive examples of Black men, while negative stereotypes are exaggerated [4] and linked to increased psychological distress [4]. The media can significantly influence a wide variety of audiences [5]. As such, it can serve as a platform to help trainees understand both systemic and individual cultural biases that influence their education, clinical practice, and patient care/outcomes.

One vibrant example is the popular NBC primetime drama: This Is Us. The show follows Jack and Rebecca Pearson, a married white couple from the 1970s to the modern day, through the lens of their adult children: Kevin, Kate, and Randall. Randall, their adopted Black son, has an anxiety disorder-providing insight into the confluence of mental illness, culture, and race. The Substance Abuse and Mental Health Services Administration reports that $16 \%$ of self-identified Black adults have a mental illness, yet only $31 \%$ of them receive treatment [6]. Additionally, for reasons not fully understood, the rate of suicide is four times higher for Black men than women [7]. These data underscore the

Jessica A. Gold

jgold@wustl.edu

1 Georgetown University School of Medicine, Washington, DC, USA

2 Yale University School of Medicine, New Haven, CT, USA

3 Boston Children's Hospital, Harvard Medical School, Boston, MA, USA

4 Washington University School of Medicine in St. Louis, St. Louis, MO, USA importance of accurate media portrayals of Black people with mental illness, but unfortunately, this remains a rarity in television. In 2016, only 19\% ( $n=11)$ of television characters with mental illness were Black [8].

This Is Us fills an instrumental role by representing mental health in Black people and starting the conversation to de-stigmatize treatment. On average, 7.6 million people tuned in to seasons 2 and 3, and watched a Black man be diagnosed with and manage an anxiety disorder [9]. Given the show's popularity, it can substantially impact public perception of Black men and Black mental health, especially as the show's audience is rather diverse (vs. US population): $79 \%$ non-Hispanic white $(60 \%), 10 \%$ non-Hispanic Black (12\%), 6\% Hispanic (18\%), 3\% non-Hispanic Asian $(6 \%)$, and $2 \%$ non-Hispanic other $(1 \%)[10,11]$. This is notably true as Randall Pearson does not fit the stereotype of a "typical" Black man in the media: an athlete or criminal [4]. Instead, Mr. Pearson is a loving father, devoted partner, and an intellectual.

Popular media can be a powerful teaching tool [5] and to that end, This is Us allows vast opportunities to help trainees think more astutely about the influence of culture and race on mental health and learn to integrate cultural humility into their practice. Through Randall's storylines, psychiatric educators can tackle essential concepts, such as implicit bias in clinicians, and address (1) interracial adoption and identity formation, (2) barriers to mental health treatment for Black men, and (3) the process of asking for help. Ultimately, Randall's story can serve as a prudent jumping-off point to help foster discussion about adopting culturally informed treatment practices among mental health providers.

\section{Randall Pearson: How Identity Shapes the Experience of Mental Health}

When considering Randall as a case study, trainees need to understand how he became a father, brother, and son. Additionally, who he is now, how he has understood his racial identity, and how that subsequently impacts his mental 
health shapes his identity. As the only Black and adopted member of a white family, Randall struggles with his background, particularly his Blackness within his home and the broader community. For example, with many activities often ascribed to Black culture (e.g., rap music), Randall grapples with being unfamiliar. In season 4 episode 2 , he is called "an Oreo" at the pool, signifying a "white experience" inside a Black body. There are also moments of microaggressions within his own family, as his white grandmother comments on how smart he is, implying this is unusual given his skin tone (season 2 episode 4 ).

In turn, Randall pursues socialization outside of his adoptive family to align more with Black culture. Research shows that exposure to their birth culture/race can significantly and positively impact adopted children's experience [12]. Also, educating about and preparing minoritized adoptees for bias they may encounter can lessen the child's risk of stress and depression [12]. This topic can be discussed in-depth with trainees using the example of the character of Mr. Lawrence, Randall's junior high teacher and a Black man with whom Randall idealizes and develops a strong attachment. He provides a safe space for Randall to explore his identity in ways he found difficult with his adoptive family (season 4 episodes 6 and 7).

Similarly, although accepted to predominantly white institutions, Randall finds great pride in his acceptance to Howard University, a Historically Black College and University. Though his adoptive parents try to encourage engagement in Black-only spaces, they repeatedly sever these ties, presumably fearful Randall will no longer be as attached to them. The most notable example of this is Randall's adoptive mother keeping his Black birth father away, revealed in season 1 episode 15 . These decisions arguably negatively affected Randall's identity formation as a Black child, surrounded by whiteness and unable to explore his birth culture to any real depth. It is likely why, in part, he seeks out his biological parents on his own to learn more and why this identity conflict is one etiology of his mental illness.

\section{Being Diagnosed with an Anxiety Disorder as a Black Man}

Randall struggles with varying degrees of anxiety throughout his life. The show displays this in great visual detail and historical context from the beginning, drawing the viewer in and making the experience more real. Randall always puts the needs of others before himself and avoids burdening anyone. To do so, and in striving for perfection, he frequently hides his emotional struggles. Like many Black men who need help and do not get it [6, 7], Randall does not ask for help and ignores his mental health needs. He subsequently has panic attacks, so severe that the show hints at prior hospitalization or emergency evaluations, when his expectations are not met, he is too busy to cope, or he can no longer suppress his emotions. This is depicted for the first time in season 1's finale. It is not until the panic attacks become too overwhelming that Randall is compelled to reach out

Table 1 Teaching GAD with Randall Pearson as a case study

DSM-5 Generalized Anxiety Disorder (GAD) Diagnostic Criteria

Excessive anxiety and worry (apprehensive expectation), occurring more days than not for at least 6 months, about a number of events or activities (such as work or school performance)

The individual finds it difficult to control the worry

The anxiety and worry are associated with three (or more) of the following six symptoms (with at least some symptoms having been present for more days than not for the past 6 months):

1. Restlessness or feeling keyed up or on edge. 2. Being easily fatigued. 3. Difficulty concentrating or mind going blank. 4. Irritability. 5 . Muscle tension. 6. Sleep disturbance

The anxiety, worry, or physical symptoms cause clinically significant distress or impairment in social, occupational, or other important areas of functioning

The disturbance is not attributable to the physiological effects of a substance (e.g., a drug of abuse, a medication) or another medical condition. The disturbance is not better explained by another mental disorder
Randall's anxiety in season 1 episode 15

Since early adolescence, Randall displayed subtle symptoms of anxiety in many situations (school, social, and home). As an adult, and particularly during this episode, his worries (work-related) become more frequent and pronounced. Temporally, his symptoms span more than 6 months

Restlessness/feeling on edge: While at work, Randall's hands are trembling and he's pacing

Mind going blank: During a presentation at work, Randall experiences a brief period of anomia

Irritability: Randall is terse at work and yelling at coworkers and other employees. He also cuts discussions short with his family

Randall experiences a feeling of being overwhelmed which results in emotional lability, including crying, tachypnea, and feeling unable to complete his work. Additionally, the episode eludes to Randall's wife acknowledging a change in his behavior over the past several months

Randall is not shown using any substances or taking any medication Randall has not been diagnosed with any other medical conditions 
for help. The origin and presentation of this suppression of emotion can prompt conversation around stigma in asking for help, especially within the Black community [13] (see Table 1 for a conceptualization of his anxiety and teaching points).

The show particularly addresses some of the issues around reaching out for help in Black men [6]. One such challenge is simply the decision to ask for help. Randall seeks counsel from two people about help-seeking, Darnell, the father of his daughter's boyfriend and a Black man, and his wife, Beth, a Black woman. In season 4 episode 11, Darnell reveals to Randall that he first attempted pastoral counseling and ultimately was referred to therapy. Darnell also discusses that he finds therapy beneficial for everyday things or deeper issues that are challenging to discuss with his wife.

Research shows that having a supportive spouse is beneficial to Black men's mental health and may even mitigate the adverse effects of stress [14]. This is highly relevant in Randall's case, where his wife repeatedly provides the push he needs to seek treatment. Ultimately, it is seeing the destruction of Beth's psychological wellness, in a strikingly vulnerable moment, in season 4 episode 15 , where Beth is honest about her struggle to "deal" with Randall's anxiety alone, that leads Randall to get help. Though much of the conversation is beyond this paper's scope, it is imperative to address the essential role of Black women in help-seeking, support, and modeling vulnerability for Black men. In this way, Beth is critical in allowing Randall to experience his full humanity worthy of help and support.

Another teaching point is the personally mediated racism Black men experience when interacting with the mental health system [15]. For instance, there is an over-diagnosis of psychotic symptoms and under-diagnosis of mood disorders in Black men [16]. Compared with white peers, Black youth are less likely to initiate or be referred for care and more likely to terminate prematurely [17]. As we know, Black youth are not in less need of these services, but Black families may not receive proper framing of mental health service engagement. For Black men, fewer health-seeking behaviors, such as attending annual doctors' appointments or going to the hospital for emergency care, can be partially attributed to these earlier messages [18]. Mental health providers must understand these barriers in order to address them. There is also utility in employing different communities, such as faith [19], peers, and Black women as motivators in helping Black men gain access to treatment, as both Darnell and Beth provided for Randall.

Current outreach to the Black community centers on health promotion in Black social spaces, such as churches, to increase mental health awareness in this population [19]. Such community efforts have generally focused on symptom recognition or screening. Despite these programs, there remains a paucity of engagement in treatment-particularly with Black men, who continue to experience many barriers to care. Additionally, though most Black men do not seek care, when they do they may endure additional bias [20]. Psychiatric disorders in Black male adolescents may be misdiagnosed due to atypical presentation [21]. As untreated anxiety and trauma are prominent precursors to suicide, leading to increasing rates of suicide among Black male youth over the past decades, correct diagnosis is critical [22]. This requires an assessment and understanding of biases. Trainees can use Randall as a case study to talk about their own (see Table 2). Clinicians can be reticent to address trauma or appropriately diagnose psychotic disorders due to unconscious bias or lack of training in cultural humility [16]. In teaching, Randall's narrative can act as an entertaining and thought-provoking case study and catalyst to begin this conversation, centering on Black people's humanity and the need for care.

Table 2 Methods to reduce clinician bias (adapted from Hairston et al. 2019 [15])

\begin{tabular}{ll}
\hline Categories & Examples \\
\hline Provide culturally informed care & - Be aware of cultural differences in the patient's identified racial/ethnic group \\
& - Consider how the social determinants can impact patient outcomes \\
& - Appreciate and acknowledge the history of structural racism and how it has affected a patient's from racial/ \\
& ethnic minoritized populations \\
& - Acknowledge individual variation in a patient's experiences \\
& - Examine one's therapeutic practices for bias and reflect on personal biases \\
& - Educate oneself about ingroup/outgroup bias \\
Clinician self-awareness & - Participate in formal bias reduction training \\
& - Reduce bias on a daily basis by examining others' perspectives, spending more time with people from \\
& diverse backgrounds, and acting in opposition to stereotypes \\
& - Follow diagnostic and treatment standards of care \\
Build clinician-patient alliance & - Avoid applying stereotypes to patient behavior or symptoms \\
& - Be aware of treatment preferences and review them with the patient \\
& - In an effort to increase trust in the therapeutic relationship and build rapport, consider openly discussing \\
imparity in the patient's and clinician's cultural backgrounds when applicable
\end{tabular}


As with Randall, depictions and self-disclosure of mental illness can help with education and help change public opinion. Broad-reaching, culturally sensitive treatment is wholly needed and takes dedicated training, research, and time. This Is Us may elicit community change by modeling careseeking and actual treatment by a Black man on screen. We see this not merely through fictitious characters but also in real-life. For example, Black male hip-hop artist Kid Cudi's self-disclosure of depression initiated integral discussions about how Black men with depression can engage in treatment [23]. Therefore, we infer that showing Randall's struggles may have a similar impact on individuals at home and contribute to the greater narrative of Black men deserving of care and support.

\section{Teaching Mental Health in Black Men in Psychiatry: Randall Pearson as a Case Study}

Just as Randall's character can help normalize mental illness and therapy in the Black community, his story can also educate about culturally informed mental health treatment approaches. Given that the show's audience is predominantly white [10], showcasing his experiences can increase dialogues about race and mental illness in larger public discourse. In psychiatric and other graduate medical education training, Randall's case can spark discussions on cultural humility, personally mediated racism leading to misdiagnosis, and barriers Black men encounter to access treatment.

While the role of adoption was previously discussed, understanding identity consolidation for Black men in the USA and the media's role is also critical to understanding Randall. He comes of age in the 1980s in a white family and must learn what it means to be Black in America, often left to deal with anti-Black racism in the news on his own. This narrative allows trainees to examine how race and racism impact the moral and psychological development of Black men. For example, Black boys as young as ten years old are not viewed as innocent like their white peers but are instead more likely to be mistaken as older, perceived as guilty, and face police violence [24]. As early as pre-school, teachers are more likely to perceive Black males as exhibiting deviant behavior even if none exists, resulting in disproportionately elevated suspension rates [25]. Applying these adult labels to boys robs them of their childhood. Understanding how this shapes a Black male's psychological development and discussing it is critical to becoming a culturally informed mental health specialist.

Randall's encounters in therapy also illustrate how white clinicians can handle the biases and cultural differences that can invade the therapeutic relationship and can prompt conversations on these important topics. In season 4 episode
15 , the white female therapist, aware of her bias, directly confronts Randall about choosing a therapist that demographically mirrors his adoptive mother. In real therapeutic settings, clinicians must highlight observations related to race while also addressing their own biases and how they may affect the therapeutic relationship. While doing this may risk rupturing the dynamic, it can also inform patients of the value of seeing a clinician with similar cultural background by openly naming the potential barriers to safety and trust in the room.

Discrepancies in racial pairing between patients and clinicians can impact diagnosis and treatment [15], so clinicians must take the onus to reduce their biases. This may include formal bias training and educating themselves about the history of racism and discrimination against minoritized people in medicine and that connection to current resistance to treatment. Other suggested methods are provided in a nonexhaustive list in Table 2. By confronting Randall, the therapist spurred his realization that he was not comfortable sharing everything with her, thereby undermining his healing. In season 5 episode 3 , he starts to see a Black male therapist, which provides Randall the space to examine major events like George Floyd's murder, his birth mother's history, and even his transracial adoption for the first time-all while actively using his support system and without panic attacks. Discussing this change in his comfort is key to trainees truly understanding identity and race.

As videos of Black men being killed replay on television, are shared on social media, and become viral on the internet, collective Black trauma is likely occurring [3], and public biases are forming. Trainees must understand mental health in their Black patients, where their symptoms originate, and what barriers to care are created. They also need to assess their own biases. Randall's storylines can help them begin to counter harmful stereotypes founded in racism and serve as a teaching tool for mental health specialists to better care for Black men in the future. On a grander scale, Randall's experience may serve as a pseudo- "celebrity disclosure" through which Black men can identify and encourage treatment-seeking, instead of delay. There will be one more positive portrayal in the media, which is sorely needed.

Funding Funding for this project was made possible to Kevin Simon (in part) by grant no. 5H79TI081358 from SAMHSA. The views expressed do not necessarily reflect the official policies of the Department of Health and Human Services, nor does mention of trade names, commercial practices, or organizations imply endorsement by the US government. Ayana Jordan's work is supported by grants from the Principal Investigator's departmental funds at Yale University and Yale Center for Clinical Investigation CTSA under award number KL2TR001862; and from the National Center for Advancing Translational Science (NCATS), components of the National Institutes of Health (NIH), and NIH roadmap for Medical Research. Dr. Gold 
receives financial compensation from ViacomCBS to be a member of the Mental Health Storytelling Initiative Expert Advisory Council.

\section{Declarations}

Disclosures On behalf of all authors, the corresponding author states that there is no conflict of interest.

\section{References}

1. Centers for Disease Control. COVID-19 in racial and ethnic minority groups. 2020. https://www.cdc.gov/coronavirus/2019ncov/need-extra-precautions/racial-ethnic-minorities.html. Accessed 28 May 2020.

2. Jordan A, Allsop AS, Collins PY. Decriminalising being Black with mental illness. Lancet Psychiatry. 2021;8(1):8-9.

3. Bor J, Venkataramani AS, Williams DR, Tsai AC. Police killings and their spillover effects on the mental health of Black Americans: a population-based, quasi-experimental study. Lancet. 2018;392(10144):302-10.

4. Tukachinsky R, Mastro D, Yarchi M. The effect of prime time television ethnic/racial stereotypes on Latino and Black Americans: a longitudinal national level study. J Broadcast Electron Media. 2017;61(3):538-56.

5. Morgan M, Shanahan J. The state of cultivation. J Broadcast Electron Media. 2010;54(2):337-55.

6. Substance Abuse and Mental Health Services Administration. Key substance use and mental health indicators in the United States: results from the 2019 National Survey on Drug Use and Health (HHS Publication No. PEP20-07-01-001). Rockville, MD: Center for Behavioral Health Statistics and Quality, Substance Abuse and Mental Health Services Administration; 2020. https:// www.samhsa.gov/data/sites/default/files/reports/rpt29393/2019N SDUHFFRPDFWHTML/2019NSDUHFFR1PDFW090120.pdf. Accessed 5 June 2021.

7. Murphy SL, Xu J, Kochanek KD, Arias E, Tejada-Vera B. Deaths: final data for 2018. Natl Vital Stat Rep. 2021;69(13):1-83.

8. Smith SL, Choueiti M, Choi A, Pieper K, Moutier C. Mental health conditions in film \& TV: portrayals that dehumanize and trivialize characters. USC Annenberg Inclusion Initiative; 2019. http://assets.uscannenberg.org/docs/critics-choice-2.pdf. Accessed 26 May 2020.

9. This Is Us: season four ratings. https://tvseriesfinale.com/tv-show/ this-is-us-season-four-ratings/. Accessed 29 July 2020.

10. The Nielsen Company. From demographics to devices: modern media across the masses. 2018. https://s3.amazonaws.com/media. mediapost.com/uploads/fromdemostodevices.pdf. Accessed 5 June 2021.

11. United States Census Bureau. 2018: ACS 5-Year Estimates Data Profiles. 2019. https://data.census.gov/cedsci/table?d=ACS\%
205-Year\%20Estimates\%20Data\%20Profiles \& tid=ACSDP 5Y2018.DP05. Accessed 11 July 2020.

12. Presseau C, DeBlaere C, Luu LP. Discrimination and mental health in adult transracial adoptees: can parents foster preparedness? Am J Orthopsychiatry. 2019;89(2):192-200.

13. Vinson ES, Abdullah T, Brown TL. Mental illness stigma intervention in African Americans: examining two delivery methods. J Nerv Ment Dis. 2016;204(5):400-3.

14. Kiecolt KJ, Hughes M, Keith VM. Race, social relationships, and mental health. Pers Relat. 2008;15(2):229-45.

15. Hairston D, Gibbs TA, Wong SS, Jordan A. Clinician bias in diagnosis and treatment. In: Medlock MM, Shtasel D, Trinh N-HT, Williams DR, editors. Racism in psychiatry: contemporary issues and interventions. 1st ed. Cham: Springer International Publishing : Imprint: Humana; 2019. p. 105-30. (Current Clinical Psychiatry).

16. Gara MA, Vega WA, Arndt S, et al. Influence of patient race and ethnicity on clinical assessment in patients with affective disorders. Arch Gen Psychiatry. 2012;69(6):593-600.

17. Marrast L, Himmelstein DU, Woolhandler S. Racial and ethnic disparities in mental health care for children and young adults. Int J Health Serv. 2016;46(4):810-24.

18. Eley NT, Namey E, McKenna K, Johnson AC, Guest G. Beyond the individual: social and cultural influences on the health-seeking behaviors of African American men. Am J Men's Health. 2019;13(1): 1557988319829953.

19. Hankerson SH, Lee YA, Brawley DK, Braswell K, Wickramaratne PJ, Weissman MM. Screening for depression in African-American churches. Am J Prev Med. 2015;49(4):526-33.

20. Motley R, Banks A. Black males, trauma, and mental health service use: a systematic review. Perspect Soc Work. 2018;14(1):4-19.

21. Baglivio MT, Wolff KT, Piquero AR, Greenwald MA, Epps N. Racial/ethnic disproportionality in psychiatric diagnoses and treatment in a sample of serious juvenile offenders. J Youth Adolesc. 2017;46(7):1424-51.

22. Lindsey MA, Sheftall AH, Xiao Y, Joe S. Trends of suicidal behaviors among high school students in the United States: 19912017. Pediatrics. 2019;144(5):e20191187.

23. Francis DB. Young black men's information seeking following celebrity depression disclosure: implications for mental health communication. J Health Commun. 2018;23(7):687-94.

24. Goff PA, Jackson MC, Leone Di, Lewis Brooke Allison, Culotta CM, DiTomasso NA. The essence of innocence: consequences of dehumanizing black children. J Pers Soc Psychol. 2014;106(4):526-45.

25. US Department of Education: Office for Civil Rights. 2013-2014 Civil rights data collection. 2016. https://www2.ed.gov/about/offic es/list/ocr/docs/2013-14-first-look.pdf. Accessed 28 May 2020.

Publisher's Note Springer Nature remains neutral with regard to jurisdictional claims in published maps and institutional affiliations. 